\title{
Daily eating frequency and cardiometabolic risk factors in young Australian adults: cross-sectional analyses
}

\author{
Kylie J. Smith ${ }^{1 *}$, Leigh Blizzard ${ }^{1}$, Sarah A. McNaughton ${ }^{2}$, Seana L. Gall ${ }^{1}$, Terence Dwyer ${ }^{3}$ and \\ Alison J. Venn ${ }^{1}$ \\ ${ }^{1}$ Menzies Research Institute, Private Bag 23, Hobart, Tasmania 7001, Australia \\ ${ }^{2}$ Centre for Physical Activity and Nutrition Research, Deakin University, 221 Burwood Highway, \\ Burwood, VIC 3125, Australia \\ ${ }^{3}$ Murdoch Children's Research Institute, Parkville, VIC 3052, Australia \\ (Submitted 4 May 2011 - Final revision received 12 October 2011 - Accepted 24 October 2011 - First published online 16 December 2011)
}

\begin{abstract}
Eating frequency may be important in the development of overweight and obesity and other cardiometabolic risk factors; however, the evidence is inconsistent. The aim of the present study was to examine the associations between the number of eating occasions and cardiometabolic risk factors in a national population-based sample of young adults. A cohort of 1273 men and 1502 women, aged 26-36 years, completed a meal pattern chart to record when they had eaten during the previous day (in hourly intervals). The total number of eating occasions was calculated. Diet quality was assessed, waist circumference was measured and a fasting blood sample was taken. Dietary intake was compared with the Australian Guide to Healthy Eating. The associations between the number of eating occasions and cardiometabolic risk factors were calculated using linear regression. Analyses were adjusted for age, education and physical activity. Most men ate three to five times per $\mathrm{d}$ and most women ate four to six times. The proportion of participants meeting dietary recommendations increased with the number of eating occasions. For men, an additional eating occasion was associated with reductions in mean values for waist circumference $(-0.75 \mathrm{~cm})$, fasting glucose $(-0.02 \mathrm{mmol} / \mathrm{l})$, fasting insulin $(-0.34 \mathrm{mU} / \mathrm{l} ; 2.04 \mathrm{pmol} / \mathrm{l})$, TAG $(-0.03 \mathrm{mmol} / \mathrm{l})$, total cholesterol $(-0.08 \mathrm{mmol} / \mathrm{l})$ and LDL-cholesterol $(-0.06 \mathrm{mmol} / \mathrm{l})$. Adjustment for waist circumference attenuated the results. Significant trends were not observed for women. In conclusion, a higher number of eating occasions were associated with reduced cardiometabolic risk factors in men. Many associations were mediated by waist circumference.
\end{abstract}

Key words: Eating frequency: Cardiometabolic risk: Abdominal obesity: Insulin: Lipids

There is some evidence that in recent decades, individuals have moved away from eating three meals per $d$ to eating more frequently. Data from large nationally representative surveys suggest that adults in the USA are consuming foods more frequently throughout the day than 30 years ago ${ }^{(1)}$. Between 1977-8 and 2003-6, the median number of eating occasions increased from 3.5 times per $\mathrm{d}$ to five times per $\mathrm{d}$.

Over the same time period, the prevalence of overweight and obesity has also increased, which raises the question of whether increased eating frequency is associated with adiposity. Some early epidemiological studies have reported an inverse association between eating frequency and body weight ${ }^{(2)}$; however, more recent epidemiological studies have suggested that the inverse association was a result of reporting bias $^{(3)}$. Several ${ }^{(4,5)}$, but not all, ${ }^{(6,7)}$ studies that exclude under-reporters and/or adjust for physical activity have shown that the inverse association disappears. A review of weight-loss and weight-maintenance trials has reported no benefit of a higher eating frequency on weight loss ${ }^{(8)}$. There is some evidence that increased eating frequency is associated with greater appetite control ${ }^{(9,10)}$, and this may result in reduced total energy intake and weight loss. Randomised controlled trials examining the effect of eating frequency on body weight have controlled for energy intake, which would prevent investigation of this causal pathway ${ }^{(11)}$.

In addition to adiposity, eating frequency has also been reported to be associated with other cardiometabolic risk factors. A recent review of eight randomised cross-over trials investigated which meal pattern, 'feasting' (consuming all daily energy needs in one large meal each day) or 'nibbling'

Abbreviations: CDAH, Childhood Determinants of Adult Health; HOMA, homeostasis model assessment.

*Corresponding author: K. J. Smith, fax +6136226 7755, email k.j.smith@utas.edu.au 
(eating several small meals over a day), was best for CVD prevention $^{(12)}$. The authors reported a weak dose-response relationship, with a reduction in total and LDL-cholesterol concentrations as the number of meals consumed per $d$ increased and concluded six or more meals per $\mathrm{d}$ may reduce the risk of CVD in non-diabetic, normal-weight and obese individuals. Trials examining the effect of eating frequency on glucose metabolism have reported mixed results, showing either a beneficial effect or no association ${ }^{(8)}$.

It is not clear what effect eating frequency has on cardiometabolic risk factors when food is consumed ad libitum. In addition, it is unclear whether findings from controlled trials can be generalised to population settings.

The aims of the present study were to determine whether eating frequency was associated with cardiometabolic risk factors in a national sample of young adults, and to determine whether any associations were confounded by physical activity or mediated by diet quality or waist circumference.

\section{Methods}

The Childhood Determinants of Adult Health (CDAH) Study is a follow-up of children who participated in the 1985 Australian Schools Health and Fitness Survey, a nationally representative study of 8498 children aged $7-15$ years ${ }^{(13)}$. During 2001-2, 6840 (80\%) participants were traced and 5170 (76\%) were enrolled in the CDAH study. Participants were invited to attend one of thirty-four study clinics held in each state and territory of Australia. The clinics included a range of physical measures including anthropometric measurements and the collection of a fasting blood sample and were attended by 2410 participants (aged 26-36 years) during 2004-6. Questionnaires were completed to collect data on demographics, diet and physical activity. The study was conducted according to the guidelines laid down in the Declaration of Helsinki and all procedures involving human participants were approved by the Southern Tasmanian Health and Medical Research Ethics Committee. Written informed consent was obtained from all participants.

\section{Dietary assessment}

Diet was assessed using a meal pattern chart, a food habits questionnaire and a FFQ. The meal pattern chart divided the day into hourly intervals from 06.00 to 23.00 hours and the hours 23.00 to 06.00 were combined as a single time period. Participants were asked to think back to the previous day and for each interval, participants were asked 'Did you eat anything?' Response options were 'no', 'a snack', 'a small meal' or 'a large meal'. Examples of each meal type were given. Information on drinks consumed was also collected; however, drinks consumed on their own were not included as eating occasions ${ }^{(4)}$. A similar method for measuring meal patterns has been used in a previous study of adults ${ }^{(14)}$. In that study, a subsample of participants completed the meal pattern chart a second time 3 months later and showed good retest reliability ${ }^{(14)}$.
The FFQ included 127 food and beverages. Participants were asked to estimate how many times in the previous 12 months they had consumed each item using one of six response options ranging from 'never/less than once per month' to ' $6+$ times per d'. The questionnaire did not collect information on serving sizes. Participants who did not answer at least $90 \%$ of the FFQ were excluded from the analyses (thirty-five men and fifty-two women). The FFQ was a modified version of one previously used in the 1995 Australian National Nutrition Survey ${ }^{(15-18)}$ and was based on an existing FFQ developed for Australian populations ${ }^{(19)}$ but has not been validated with weighed food records.

The food habits questionnaire asked short questions about food-related behaviours. Usual daily intakes of fruit and vegetables were estimated using the questions 'How many serves of fruit do you usually eat each day?' and 'How many serves of vegetables (excluding potatoes) do you usually eat each day?' Short questions have been shown to be a valid method of assessing fruit and vegetable intake ${ }^{(20)}$. Participants were also asked whether they were currently following a special diet (vegetarian, weight reduction, diabetic, fat modified, other, no special way of eating).

Diet quality was assessed by comparing participants' dietary intake with the age- and sex-specific recommendations in the Australian Guide to Health Eating ${ }^{(21)}$. Daily serves of breads and cereals, dairy, lean meat and alternatives, and extra foods (those that do not fit into the five core food groups $^{(21)}$ ) were calculated ${ }^{(22)}$. To calculate the overall dietary score, points were given for each component of the diet for which recommended intake was achieved (score range 0-6).

\section{Anthropometric measurements}

For the anthropometric measurements, participants were standing, wearing light clothing and no shoes. All technicians were trained by the same anthropometrist and followed standardised protocols. Waist circumference was measured three times using a Lufkin steel (non-stretch) tape measure at the narrowest point between the lower costal border and the iliac crest at the end of normal expiration. The mean value was used for the analysis. Body weight was measured using a Heine portable scale (Heine) and height was measured using a portable stadiometer (Invicta). BMI $\left(\mathrm{kg} / \mathrm{m}^{2}\right)$ was calculated.

\section{Blood chemistry}

Venous blood samples were collected from the antecubital vein after an overnight fast. Fasting glucose, TAG, total cholesterol and HDL-cholesterol concentrations were determined enzymatically using an Olympus AU5400 automated analyser (Olympus Optical). LDL-cholesterol concentration was calculated using the Friedewald formula ${ }^{(23)}$. Fasting insulin concentration was determined using two methods: a microparticle enzyme immunoassay kit (AxSYM; Abbott Laboratories) and electrochemiluminescence immunoassay (Elecsys Modular Analytic E170; Roche Diagnostics). A correction factor of 0.81 was applied to the insulin values assessed with the 
microparticle enzyme immunoassay. Insulin sensitivity was estimated by the homeostasis model assessment (HOMA) index ((fasting serum insulin $(\mathrm{U} / \mathrm{ml}) \times$ fasting glucose $(\mathrm{mmol} / \mathrm{l})) / 22 \cdot 5)$.

\section{Blood pressure}

Blood pressure was measured three times with a digital automatic monitor (Omron HEM907; Omron Health Care, Inc.). The mean value was used in the analyses.

\section{Metabolic score}

A continuous metabolic syndrome score was created, using the methods described by Wijndaele et al. ${ }^{(24,25)}$.

\section{Covariates}

Demographic variables were self-reported and included age, marital status (married or living as married, other), highest level of education (school only, vocational, university), occupation (professional or manager, non-manual, manual, not in the workforce), smoking status (never, former, current smoker) and parity $(0,1,2, \geq 3)$. Parity was considered as a confounder because we thought women with children may be more likely to be overweight or obese and having children may result in a more regular eating pattern. However, parity was not found to be a significant confounder and was not included in the final models. Leisure-time physical activity (LTPA) and time spent sitting were assessed using the long version of the International Physical Activity Questionnaire ${ }^{(26)}$. Participants also wore a pedometer (Yamax Digiwalker SW 200) for $7 \mathrm{~d}$. The average number of daily steps was calculated for participants who reported wearing the pedometer for at least $8 \mathrm{~h}$ on at least $4 \mathrm{~d}$. Time spent watching television was also assessed $^{(27)}$. Weekly alcohol consumption was estimated from nine alcoholic beverages in the FFQ and their average alcohol concentration $^{(28)}$.

\section{Statistical analysis}

The mean and standard deviation number of each meal and snack type and the overall number of eating occasions were calculated. The number of eating occasions was collapsed into six categories $(1-2,3,4,5,6$ and $7+$ times per d) due to the small number of people who were eating once or twice per $d$ and those who were eating seven or more times. We chose not to group the eating frequency into groups such as 'nibbling', 'grazing' or 'gorging' as others have done $\mathrm{e}^{(12,29-33)}$ because there is no consistency in the definition of these categories and no evidence in our data of threshold values that would support any such categorisation. A test of trend in the mean number of each meal type with eating frequency was estimated using a Poisson regression model. A test of trend in proportions meeting the dietary recommendations was estimated with a log binomial regression model. In each case, the $P$ value reported is a test of significance of the coefficient of a linear predictor taking values equal to the mean number of eating occasions in each category (the mean for category $1-2$ was 1.88 times per $\mathrm{d}$ and the mean for category $7+$ was 7.52 times per $d$ ).

The associations between eating frequency and cardiometabolic risk factors were estimated using linear regression. The cardiometabolic variables were transformed as required to reduce skewness, but all estimates are reported in the original units. Covariates added to the model were those that were associated with the outcome, were not intermediates between the exposure and the outcome and, when included in the model, changed the coefficient of the variable for the principal study factor by $>10 \%{ }^{(34)}$. Participants who were missing information for covariates were excluded from the analyses presented in Table 4. Excluding these participants (101 men and seventy-six women) from the summary data reported in Tables 1-3 made almost no difference to those results. Model 1 adjusted for age, education and, for women, alcohol intake. LTPA was added to model 2. To examine whether any associations were mediated by diet quality, model 3 included additional adjustments for the overall dietary score. Model 4 included adjustment for waist circumference. The effect of one additional eating occasion on cardiometabolic risk factors was calculated at the mean values of the other covariates.

Pregnant women $(n$ 78) were excluded from all analyses. The analyses were repeated excluding individuals who

Table 1. Sociodemographic and lifestyle characteristics of the participants*

(Number of participants and percentages)

\begin{tabular}{|c|c|c|c|c|}
\hline & \multicolumn{2}{|c|}{$\begin{array}{c}\text { Men } \\
(n 1273)\end{array}$} & \multicolumn{2}{|c|}{$\begin{array}{l}\text { Women } \\
(n \text { 1502) }\end{array}$} \\
\hline & $n$ & $\%$ & $n$ & $\%$ \\
\hline \multicolumn{5}{|l|}{ Age (years) } \\
\hline Mean & \multicolumn{2}{|c|}{$31 \cdot 7$} & \multicolumn{2}{|c|}{31.5} \\
\hline SD & \multicolumn{2}{|c|}{2.6} & \multicolumn{2}{|c|}{2.6} \\
\hline \multicolumn{5}{|l|}{ Marital status } \\
\hline Single & 421 & $33 \cdot 1$ & 438 & $29 \cdot 2$ \\
\hline Married & 852 & $66 \cdot 9$ & 1063 & $70 \cdot 8$ \\
\hline \multicolumn{5}{|l|}{ Education } \\
\hline University & 437 & $37 \cdot 3$ & 671 & $44 \cdot 7$ \\
\hline Vocational & 455 & 35.9 & 388 & $25 \cdot 9$ \\
\hline No post-secondary education & 341 & $26 \cdot 9$ & 441 & $29 \cdot 4$ \\
\hline \multicolumn{5}{|l|}{ Occupation } \\
\hline Professional/manager & 717 & $57 \cdot 1$ & 714 & $48 \cdot 4$ \\
\hline Non-manual & 95 & $7 \cdot 6$ & 398 & $27 \cdot 0$ \\
\hline Manual & 398 & $31 \cdot 7$ & 74 & $5 \cdot 0$ \\
\hline Not in workforce & 45 & 3.6 & 288 & $19 \cdot 5$ \\
\hline \multicolumn{5}{|c|}{ Leisure-time physical activity (min/week) } \\
\hline Mean & \multicolumn{2}{|c|}{174.4} & \multicolumn{2}{|c|}{$156 \cdot 1$} \\
\hline SD & \multicolumn{2}{|c|}{$222 \cdot 1$} & \multicolumn{2}{|c|}{184.9} \\
\hline \multicolumn{5}{|l|}{ Steps (steps/d) } \\
\hline Mean & \multicolumn{2}{|c|}{$9239 \cdot 0$} & \multicolumn{2}{|c|}{8893.4} \\
\hline SD & \multicolumn{2}{|c|}{$3560 \cdot 4$} & \multicolumn{2}{|c|}{$3064 \cdot 2$} \\
\hline \multicolumn{5}{|l|}{ Television viewing (h/week) } \\
\hline Geometric mean & \multicolumn{2}{|c|}{11.4} & \multicolumn{2}{|c|}{$9 \cdot 6$} \\
\hline SD & \multicolumn{2}{|c|}{13.5} & \multicolumn{2}{|c|}{$10 \cdot 7$} \\
\hline \multicolumn{5}{|l|}{ Parity } \\
\hline 0 & - & - & 119 & $17 \cdot 7$ \\
\hline 1 & - & - & 185 & $27 \cdot 5$ \\
\hline 2 & - & - & 259 & 38.5 \\
\hline $3+$ & - & - & 109 & $16 \cdot 2$ \\
\hline
\end{tabular}

* Due to some missing data, numbers do not always add up to 1273 for men and 1502 for women. 
reported they were on a weight-loss diet (men $n$ 29, women $n$ 117) or were taking diabetes medication (men $n 6$, women $n$ 8). Data for men and women were analysed separately. All statistical analyses were conducted using STATA software (version 10.1; 2009 Statacorp).

\section{Results}

In total, 1273 men and 1502 non-pregnant women completed the meal pattern chart. The sociodemographic and lifestyle characteristics of the participants are shown in Table 1. Compared with the Australian population of 25-34-year-olds, the $\mathrm{CDAH}$ sample had a higher percentage who were married or living as married ( $57 \%$ of men and $64 \%$ of women in the Australian population ${ }^{(35)}$ ) and a higher percentage who were employed as professionals or managers ( $40 \%$ of men and $38 \%$ of women in the Australian population $\left.{ }^{(36)}\right)$. The percentage classified as being overweight or obese (BMI $\geq 25 \mathrm{~kg} / \mathrm{m}^{2}$ ) was very similar to the Australian population ( $58 \%$ of men and $35 \%$ of women ${ }^{(37)}$ ).

Men reported eating between one and fourteen times per $\mathrm{d}$ (Fig. 1). Most men reported eating three (24.3\%), four (27.3\%) or five $(22 \cdot 1 \%)$ times per $\mathrm{d}$. For women, the number of eating occasions ranged from one to eleven times per $\mathrm{d}$, and most reported eating four $(23.8 \%)$, five $(29 \cdot 0 \%)$ or six $(20 \cdot 2 \%)$ times per $\mathrm{d}$.

The mean number of all three meal types (large meals, small meals and snacks) increased with the number of eating occasions for both men and women $(P<0.05$; see Table S1 of the supplementary material, available online at http:// www.journals.cambridge.org/bjn). Snacks were the greatest single contributor when eating more than four times per $\mathrm{d}$.

As the number of eating occasions increased, the percentage of participants meeting the dietary recommendations increased, with the exception of breads and cereals and extra foods for men and vegetables and extra foods for women (Table 2). The mean dietary score also increased as the number of eating occasions increased for both men and women.

For men, the mean values for cardiometabolic risk factors tended to decrease with increased eating frequency (the exceptions were HDL-cholesterol and blood pressure; Table 3). For women, the only significant trend was for total cholesterol.

The coefficients reported in Table 4 are estimates of the difference in cardiometabolic risk factors associated with one additional eating occasion calculated at the mean number of eating occasions (4.39 times per $\mathrm{d}$ for men and 4.75 times per $\mathrm{d}$ women). Generally, the associations between eating frequency and cardiometabolic risk factors were not changed by adjusting for LTPA (model 2). Additional adjustments for diet quality tended to reduce the magnitude of the associations but the statistical significance did not change (model 3). Further adjustment for waist circumference attenuated the associations for men, particularly for TAG, insulin and HOMA (model 4). After adjustment, the negative association between HDL-cholesterol and eating occasions for men

Table 2. Participants meeting the recommended number of daily serves for each food group ${ }^{*}$ by number of eating occasions (Number of participants and percentages)

\begin{tabular}{|c|c|c|c|c|c|c|c|c|c|c|c|c|c|}
\hline \multirow[b]{3}{*}{ Food group } & \multicolumn{13}{|c|}{ Number of eating occasions } \\
\hline & \multicolumn{2}{|c|}{$1-2$} & \multicolumn{2}{|c|}{3} & \multicolumn{2}{|c|}{4} & \multicolumn{2}{|c|}{5} & \multicolumn{2}{|c|}{6} & \multicolumn{2}{|c|}{$7+$} & \multirow[b]{2}{*}{$P$ (trend in proportions) } \\
\hline & $n$ & $\%$ & $n$ & $\%$ & $n$ & $\%$ & $n$ & $\%$ & $n$ & $\%$ & $n$ & $\%$ & \\
\hline Men & \multicolumn{2}{|c|}{$n 75$} & \multicolumn{2}{|c|}{$n 298$} & \multicolumn{2}{|c|}{$n 339$} & \multicolumn{2}{|c|}{$n 270$} & \multicolumn{2}{|c|}{$n 166$} & \multicolumn{2}{|c|}{$n 85$} & \\
\hline Breads and cereals $(6-12)$ & 1 & 1.3 & 12 & 4.0 & 14 & $4 \cdot 1$ & 10 & 3.7 & 12 & $7 \cdot 2$ & 6 & $7 \cdot 1$ & 0.040 \\
\hline Vegetables (5) $\dagger$ & 4 & $5 \cdot 3$ & 15 & $5 \cdot 1$ & 25 & 7.4 & 24 & 8.9 & 9 & 5.4 & 12 & $14 \cdot 1$ & 0.035 \\
\hline Fruit (2) $\dagger$ & 17 & $21 \cdot 7$ & 92 & $31 \cdot 2$ & 125 & 36.9 & 110 & $40 \cdot 9$ & 79 & 47.6 & 53 & $62 \cdot 4$ & $<0.001$ \\
\hline Dairy (2) & 21 & $28 \cdot 0$ & 92 & 30.9 & 127 & 37.5 & 119 & $44 \cdot 1$ & 70 & $42 \cdot 2$ & 42 & 49.4 & $<0.001$ \\
\hline Lean meat and alternatives (1) & 52 & $69 \cdot 3$ & 234 & 78.5 & 271 & 79.9 & 226 & 83.7 & 142 & 85.5 & 74 & $87 \cdot 1$ & $<0.001$ \\
\hline Extra foods $(0-3)$ & 11 & $14 \cdot 7$ & 17 & $5 \cdot 7$ & 16 & 4.7 & 11 & $4 \cdot 1$ & 15 & $9 \cdot 0$ & 5 & 5.9 & 0.474 \\
\hline Dietary score $\ddagger$ & & & & & & & & & & & & & $<0.001$ \\
\hline Mean & \multicolumn{2}{|c|}{1.41} & \multicolumn{2}{|c|}{1.55} & \multicolumn{2}{|c|}{$1 \cdot 71$} & \multicolumn{2}{|c|}{1.86} & \multicolumn{2}{|c|}{1.97} & \multicolumn{2}{|c|}{$2 \cdot 26$} & \\
\hline SD & \multirow{2}{*}{\multicolumn{2}{|c|}{$\begin{array}{l}0.82 \\
n 50\end{array}$}} & \multicolumn{2}{|c|}{0.96} & \multicolumn{2}{|c|}{1.01} & \multicolumn{2}{|c|}{1.02} & \multicolumn{2}{|c|}{1.09} & \multicolumn{2}{|c|}{0.98} & \\
\hline Women & & & \multicolumn{2}{|c|}{$n 222$} & \multicolumn{2}{|c|}{ n 339} & \multicolumn{2}{|c|}{$n 420$} & & & & & \\
\hline Breads and cereals $(4-9)$ & 2 & 4.0 & 28 & 12.6 & 45 & 13.3 & 78 & $18 \cdot 6$ & 60 & $20 \cdot 6$ & 30 & 24.8 & $<0.001$ \\
\hline Vegetables (5)† & 5 & $10 \cdot 0$ & 28 & $12 \cdot 6$ & 47 & 13.9 & 53 & $12 \cdot 6$ & 43 & $14 \cdot 8$ & 13 & $10 \cdot 7$ & 0.841 \\
\hline Fruit $(2) \dagger$ & 10 & $20 \cdot 0$ & 77 & 34.7 & 148 & 43.8 & 224 & 53.5 & 172 & 58.9 & 73 & $60 \cdot 3$ & $<0.001$ \\
\hline Dairy (2) & 15 & $30 \cdot 0$ & 60 & $27 \cdot 0$ & 92 & $27 \cdot 1$ & 173 & $41 \cdot 2$ & 138 & $47 \cdot 3$ & 64 & 52.9 & $<0.001$ \\
\hline Lean meat and alternatives (1) & 41 & $82 \cdot 0$ & 186 & $83 \cdot 8$ & 294 & $86 \cdot 7$ & 381 & $90 \cdot 7$ & 267 & 91.4 & 105 & $86 \cdot 8$ & 0.016 \\
\hline Extra foods $\left(1-2 \frac{1}{2}\right)$ & 4 & 8.0 & 14 & $6 \cdot 3$ & 22 & 6.5 & 19 & 4.5 & 17 & $5 \cdot 8$ & 5 & $4 \cdot 1$ & 0.257 \\
\hline Dietary score $\ddagger$ & & & & & & & & & & & & & $<0.001$ \\
\hline Mean & & 54 & & & & & & & & & & & \\
\hline SD & & 86 & & & & & & & & & & & \\
\hline
\end{tabular}

* Daily Dietary Recommendations for Australian Adults aged 19-60 years are presented in parentheses after each food group. Participants consuming at least the lower value for breads and cereals and not exceeding the upper limit for extra foods were classified as meeting the recommendation. Participants classified as meeting the vegetable recommendation were consuming at least four serves per $d$.

†Some men and women did not answer the fruit and vegetable questions, therefore there are some missing data: men eating three times per $\mathrm{d} n 296$ for vegetables and 295 for fruit; men eating five times per d $n 269$ for fruit and for vegetables; women eating four times per $\mathrm{d} n 338$ for fruit and for vegetables; women eating five times per $\mathrm{d} n 419$ for fruit; women eating six times per $\mathrm{d} n 291$ vegetables.

$\ddagger$ To calculate the dietary score, points were given for each component of the diet for which recommended intake was achieved (score range $0-6$ ). 

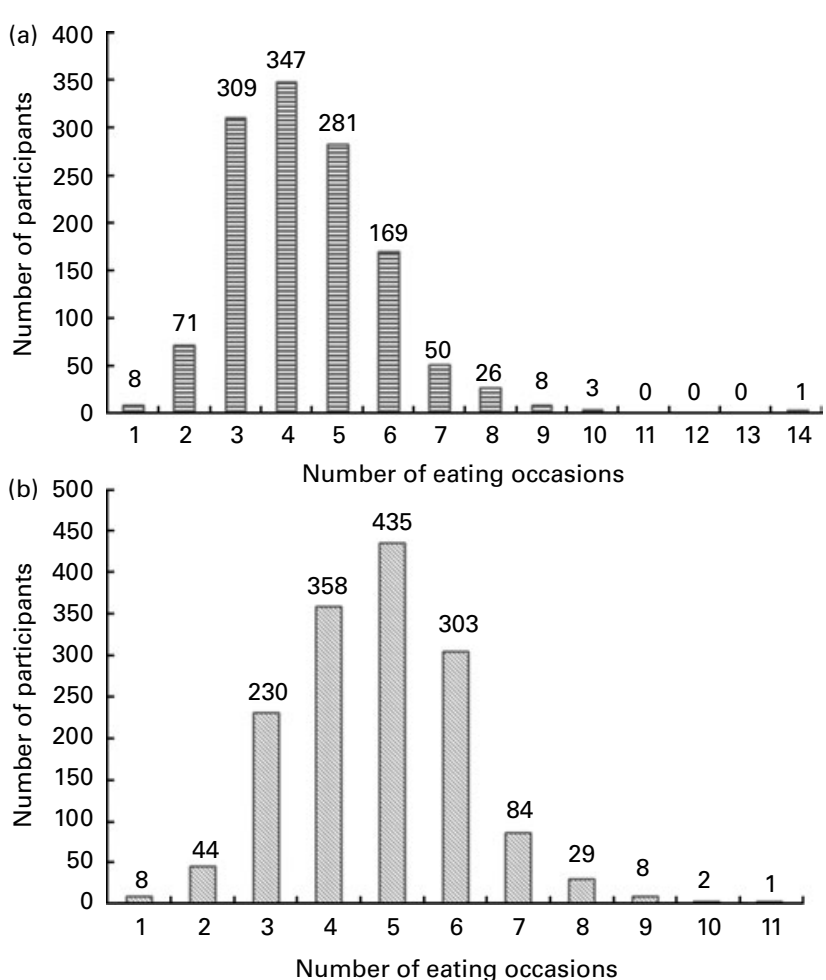

Fig. 1. Number of eating occasions for (a) men ( $n$ 1273) and (b) women ( $n$ 1502) reported during the previous day.

became statistically significant because the presence of additional covariates in the model reduced the standard error of the coefficient for eating occasions.

For men, there was a meal frequency-education interaction for BMI and an eating frequency-age interaction for HDL, where lower education and older age increased the effect of meal frequency. For women, there were eating frequencyeducation interactions for waist circumference, BMI, fasting glucose, HOMA, HDL-cholesterol and the metabolic syndrome score, where a lower education increased the effect of eating frequency except for HDL where lower education reduced the effect of eating frequency. The magnitude of effect of these interactions in each case was small for most participants.

The strength and significance of the associations did not change when the analyses were repeated in the subsample of participants who had pedometer (steps) data or when those who reported they were on a weight-loss diet or were taking diabetes medication were excluded from the analyses.

\section{Discussion}

In this sample of Australian adults, there was a linear trend between eating frequency and cardiometabolic risk factors in men, with those eating more frequently having the lowest cardiometabolic risk. There were no significant trends for women. For men, the effect on fasting insulin, HOMA and TAG appeared to be mediated by waist circumference. The association between eating frequency and fasting glucose was not explained by our measures of socio-economic or lifestyle factors, diet quality or waist circumference. Another key finding was that as the number of eating occasions increased, diet quality improved. This indicates those who ate more often were not just snacking on 'empty foods' but were choosing foods that contribute to a healthy diet.

For men, there was a negative association between eating frequency and waist circumference and BMI. The associations remained significant after adjusting for age, education and physical activity and were attenuated after adjusting for diet quality. The clinical benefits of one additional eating occasion are uncertain, though a meta-regression analysis of fifteen prospective studies reported that a $1 \mathrm{~cm}$ increase in waist circumference was associated with a $2 \%$ increased risk of a cardiovascular event ${ }^{(38)}$. We found no significant associations between eating frequency and adiposity for women. Similarly, two cross-sectional studies have reported that a higher eating frequency is associated with leanness in men but not in women, after excluding under-reporters and adjusting for physical activity ${ }^{(6,7)}$. Another cross-sectional study also reported no association between BMI and body composition measurements in premenopausal women after adjusting for physical activity ${ }^{(39)}$. In contrast, in a study of premenopausal women, eating frequency was associated with a lower waist circumference after adjusting for physical activity and $\mathrm{VO}_{2 \max }$ (as a measure of fitness), but associations with BMI and other measures of adiposity were no longer significant ${ }^{(4)}$.

The present results in men are consistent with previous epidemiological studies and randomised controlled trials that have reported that a higher eating frequency is associated with a better lipid profile. Compared with eating once or twice per $\mathrm{d}$, eating at least four times per $\mathrm{d}$ has been shown to be cross-sectionally associated with lower total and LDLcholesterol levels in men and women aged 50-81 years ${ }^{(40)}$. In a review of randomised cross-over trials, a dose-response relationship between eating frequency and total and LDLcholesterol has been reported $^{(12)}$, with clinically significant reductions $(>5 \%$ reduction) in total and LDL-cholesterol observed when at least six meals were consumed per $d$. The beneficial effects of eating more frequently were not due to weight loss, as there were no significant changes in body weight during these trials.

For men, a higher eating frequency was associated with lower concentrations of fasting glucose, insulin and a lower HOMA score. The associations with fasting insulin and HOMA appear to be mediated by abdominal obesity; however, abdominal obesity did not appear to explain the association with fasting glucose.

It is not clear why a higher eating frequency was associated with cardiometabolic benefits for men but not for women. It is possible that women who ate more often were eating unhealthy snacks and under-reported these items in the FFQ or their extra meals and snacks resulted in higher energy intakes. Another possible explanation is the different fat distribution patterns of young men and women. Men are more likely to store excess fat centrally, whereas women store it peripherally. Central adiposity is more metabolically harmful than peripheral fat. If individuals with a lower eating frequency are more likely to store fat, then this may explain why a lower eating frequency was associated with cardiometabolic risk 
Table 3. Mean cardiometabolic values for men and women by number of eating occasions* (Mean values and standard deviations)

\begin{tabular}{|c|c|c|c|c|c|c|c|c|c|c|c|c|c|}
\hline \multirow[b]{3}{*}{ Cardiometabolic variable } & \multicolumn{13}{|c|}{ Number of eating occasions } \\
\hline & \multicolumn{2}{|c|}{$1-2$} & \multicolumn{2}{|c|}{3} & \multicolumn{2}{|c|}{4} & \multicolumn{2}{|c|}{5} & \multicolumn{2}{|c|}{6} & \multicolumn{2}{|c|}{$7+$} & \multirow[b]{2}{*}{$P$ (linear trend) } \\
\hline & Mean & SD & Mean & SD & Mean & SD & Mean & SD & Mean & SD & Mean & SD & \\
\hline \multicolumn{14}{|l|}{ Men } \\
\hline Waist circumference $(\mathrm{cm})$ & $90 \cdot 08$ & 11.01 & 88.62 & 9.99 & 88.59 & $10 \cdot 61$ & 87.56 & 9.08 & 86.69 & $9 \cdot 33$ & $85 \cdot 31$ & 8.53 & $<0.001$ \\
\hline BMI $\left(\mathrm{kg} / \mathrm{m}^{2}\right)$ & 26.67 & 4.22 & 25.99 & 4.05 & $26 \cdot 02$ & $4 \cdot 15$ & $25 \cdot 84$ & 3.63 & 25.43 & 3.80 & 24.78 & $3 \cdot 28$ & 0.002 \\
\hline Fasting glucose $(\mathrm{mmol} / \mathrm{l})$ & $5 \cdot 20$ & 0.48 & $5 \cdot 14$ & 0.41 & $5 \cdot 13$ & 0.45 & $5 \cdot 11$ & 0.48 & 5.07 & 0.42 & 5.07 & 0.44 & 0.033 \\
\hline Fasting insulin $(\mathrm{mU} / \mathrm{l}) \dagger$ & $6 \cdot 89$ & $5 \cdot 25$ & $6 \cdot 81$ & 4.34 & $6 \cdot 34$ & 3.98 & $6 \cdot 37$ & 3.69 & 5.75 & 3.66 & 4.92 & $3 \cdot 13$ & $<0.001$ \\
\hline HOMA-IR & 1.60 & 1.32 & 1.56 & 1.05 & 1.45 & 0.99 & 1.45 & 0.90 & $1 \cdot 30$ & 0.87 & 1.11 & 0.75 & $<0.001$ \\
\hline $\mathrm{TAG}(\mathrm{mmol} / \mathrm{l})$ & 1.06 & 0.70 & 1.05 & 0.65 & 1.07 & 0.65 & 1.03 & 0.61 & 0.92 & 0.67 & 0.92 & 0.63 & 0.013 \\
\hline Total cholesterol $(\mathrm{mmol} / \mathrm{l})$ & $5 \cdot 10$ & 1.04 & 4.91 & 1.03 & 4.98 & 0.98 & 4.80 & 0.98 & 4.75 & 1.01 & 4.60 & 0.96 & 0.001 \\
\hline LDL-cholesterol (mmol/l) & 3.26 & 0.88 & 3.03 & 0.87 & $3 \cdot 10$ & 0.81 & 3.01 & 0.85 & 2.91 & 0.89 & $2 \cdot 81$ & 0.80 & 0.002 \\
\hline HDL-cholesterol (mmol/l) & 1.23 & 0.25 & 1.28 & 0.26 & 1.28 & 0.26 & 1.24 & 0.24 & 1.29 & 0.27 & 1.26 & 0.27 & 0.843 \\
\hline Systolic blood pressure $(\mathrm{mmHg})$ & 124.06 & $10 \cdot 26$ & 124.41 & 9.75 & $124 \cdot 29$ & 11.39 & 123.91 & $10 \cdot 85$ & 124.73 & 10.56 & $126 \cdot 25$ & 11.25 & 0.308 \\
\hline Diastolic blood pressure $(\mathrm{mmHg})$ & $75 \cdot 24$ & 8.45 & 75.02 & 8.62 & 74.91 & 8.68 & $73 \cdot 12$ & $9 \cdot 11$ & $74 \cdot 30$ & $8 \cdot 33$ & 73.88 & 9.81 & 0.088 \\
\hline Metabolic syndrome score & $0 \cdot 10$ & 0.75 & 0.00 & 0.68 & -0.01 & 0.76 & -0.06 & 0.67 & -0.18 & 0.73 & -0.18 & 0.71 & 0.002 \\
\hline \multicolumn{14}{|l|}{ Women } \\
\hline Waist circumference $(\mathrm{cm})$ & $76 \cdot 80$ & $12 \cdot 13$ & $77 \cdot 24$ & $9 \cdot 90$ & $75 \cdot 55$ & $9 \cdot 36$ & 74.88 & 8.58 & $75 \cdot 82$ & $10 \cdot 53$ & $76 \cdot 52$ & $10 \cdot 23$ & 0.348 \\
\hline BMI $\left(\mathrm{kg} / \mathrm{m}^{2}\right)$ & 24.60 & 4.71 & 24.49 & 4.45 & 23.68 & $4 \cdot 27$ & 23.63 & 3.66 & 24.09 & $4 \cdot 76$ & 23.60 & 4.53 & $0 \cdot 162$ \\
\hline Fasting glucose $(\mathrm{mmol} / \mathrm{l})$ & 4.91 & 0.45 & $4 \cdot 88$ & 0.37 & 4.80 & 0.38 & 4.79 & 0.39 & 4.85 & 0.40 & 4.77 & 0.42 & 0.104 \\
\hline Fasting insulin $(\mathrm{mU} / \mathrm{l}) \dagger$ & $6 \cdot 78$ & 4.23 & 6.44 & 3.77 & 5.91 & $3 \cdot 20$ & 5.59 & 3.07 & $6 \cdot 25$ & 3.41 & $5 \cdot 82$ & 3.69 & 0.162 \\
\hline HOMA-IR & 1.48 & 1.00 & 1.39 & 0.85 & 1.26 & 0.72 & 1.19 & 0.69 & 1.34 & 0.79 & $1 \cdot 22$ & 0.85 & 0.096 \\
\hline $\mathrm{TAG}(\mathrm{mmol} / \mathrm{l})$ & 0.83 & 0.49 & 0.88 & 0.45 & 0.82 & 0.46 & 0.77 & 0.40 & 0.81 & 0.40 & 0.82 & 0.40 & $0 \cdot 137$ \\
\hline Total cholesterol $(\mathrm{mmol} / \mathrm{l})$ & 4.83 & $1 \cdot 17$ & 4.73 & 0.86 & 4.80 & 0.86 & 4.68 & 0.82 & 4.58 & 0.85 & 4.69 & 0.89 & 0.044 \\
\hline LDL-cholesterol (mmol/l) & $2 \cdot 76$ & 1.04 & $2 \cdot 76$ & 0.79 & 2.79 & 0.73 & 2.68 & $0 \cdot 70$ & 2.66 & 0.79 & 2.72 & 0.75 & $0 \cdot 176$ \\
\hline HDL-cholesterol (mmol/l) & 1.53 & 0.34 & 1.46 & 0.34 & 1.55 & 0.34 & 1.56 & 0.33 & 1.46 & 0.31 & 1.50 & 0.35 & 0.648 \\
\hline Systolic blood pressure $(\mathrm{mmHg})$ & $110 \cdot 67$ & 9.55 & 110.05 & $10 \cdot 69$ & $110 \cdot 34$ & $9 \cdot 47$ & $110 \cdot 53$ & 9.64 & 109.95 & 9.84 & $110 \cdot 66$ & 40.49 & 0.909 \\
\hline Diastolic blood pressure $(\mathrm{mmHg})$ & $70 \cdot 66$ & $8 \cdot 21$ & 69.69 & 9.05 & 69.64 & 8.02 & 69.77 & $7 \cdot 86$ & $69 \cdot 21$ & 8.95 & $70 \cdot 29$ & $9 \cdot 12$ & 0.891 \\
\hline Metabolic syndrome score & 0.08 & 0.78 & 0.13 & 0.69 & -0.04 & 0.69 & -0.11 & 0.65 & 0.02 & 0.75 & -0.06 & 0.87 & 0.096 \\
\hline
\end{tabular}

HOMA-IR, homeostasis model assessment-insulin resistance.

*Due to some participants not having measurements for all cardiometabolic risk factors, the sample sizes vary. For men eating: 1-2 times per $d n$ 62-67; 3 times per $d n$ 237-255; 4 times per $d n$ 273-284; 5 per $d n$ 232-248; 6 times per $\mathrm{d} n$ 140-146; $7+$ times and above per $\mathrm{d} n$ 77-80. For women eating: $1-2$ times per $\mathrm{d} n$ 37-42; 3 times per $\mathrm{d} n$ 166-182; 4 times per $\mathrm{d} n$ 247-276; 5 times per $\mathrm{d} n$ 301-324; 6 times per $\mathrm{d} n$ 202-218; 7+ times and above per $\mathrm{d} n 91-100$

$\dagger 1 \mathrm{mU} / \mathrm{l}=6.00 \mathrm{pmo} / \mathrm{l}$. 
Table 4. Effect of one additional eating occasion (coefficients from regression) on cardiometabolic risk factors

( $\beta$ Coefficients and $95 \%$ confidence intervals)

\begin{tabular}{|c|c|c|c|c|c|c|c|c|}
\hline \multirow[b]{2}{*}{ Cardiometabolic risk factor } & \multicolumn{2}{|c|}{ Model $1^{*}$} & \multicolumn{2}{|c|}{ Model $2 \dagger$} & \multicolumn{2}{|c|}{ Model 3‡ } & \multicolumn{2}{|c|}{ Model $4 \S$} \\
\hline & $\beta$ & $95 \% \mathrm{Cl}$ & $\beta$ & $95 \% \mathrm{Cl}$ & $\beta$ & $95 \% \mathrm{Cl}$ & $\beta$ & $95 \% \mathrm{Cl}$ \\
\hline \multicolumn{9}{|l|}{ Men } \\
\hline Waist circumference $(\mathrm{cm})$ & -0.77 & $-1.16,-0.37$ & -0.77 & $-1.16,-0.37$ & -0.72 & $-1.12,-0.31$ & - & - \\
\hline BMI $\left(\mathrm{kg} / \mathrm{m}^{2}\right)$ & -0.26 & $-0.42,-0.11$ & -0.28 & $-0.44,-0.12$ & -0.27 & $-0.43,-0.10$ & - & - \\
\hline Fasting glucose $(\mathrm{mmol} / \mathrm{l})$ & -0.02 & $-0.04,-0.002$ & -0.02 & $-0.04,-0.002$ & -0.02 & $-0.04,-0.003$ & -0.02 & $-0.04,-0.00$ \\
\hline Fasting insulin $(\mathrm{mU} / \mathrm{l}) \|$ & -0.34 & $-0.50,-0.18$ & -0.32 & $-0.47,-0.16$ & -0.26 & $-0.42,-0.10$ & -0.06 & $-0.19,0.08$ \\
\hline HOMA-IR & -0.08 & $-0.12,-0.05$ & -0.08 & $-0.12,-0.04$ & -0.07 & $-0.10,-0.03$ & -0.02 & $-0.05,0.01$ \\
\hline TAG $(\mathrm{mmol} / \mathrm{l})$ & -0.03 & $-0.06,-0.01$ & -0.03 & $-0.06,-0.01$ & -0.03 & $-0.05,-0.001$ & -0.004 & $-0.03,0.02$ \\
\hline Total cholesterol $(\mathrm{mmol} / \mathrm{l})$ & -0.08 & $-0.12,-0.03$ & -0.07 & $-0.12,-0.03$ & -0.06 & $-0.10,-0.01$ & -0.04 & $-0.09,0.001$ \\
\hline LDL-cholesterol (mmol/l) & -0.06 & $-0.10,-0.02$ & -0.05 & $-0.09,-0.02$ & -0.04 & $-0.08,-0.003$ & -0.03 & $-0.07,0.01$ \\
\hline HDL-cholesterol (mmol/l) & -0.001 & $-0.01,0.01$ & -0.003 & $-0.01,0.01$ & -0.004 & $-0.01,0.01$ & -0.01 & $-0.02,-0.00$ \\
\hline Systolic blood pressure $(\mathrm{mmHg})$ & 0.24 & $-0.22,0.71$ & 0.21 & $-0.26,0.68$ & 0.19 & $-0.29,0.67$ & 0.33 & $-0 \cdot 14,0.81$ \\
\hline Diastolic blood pressure $(\mathrm{mmHg})$ & -0.34 & $-0.72,0.04$ & -0.36 & $-0.74,0.02$ & -0.28 & $-0.67,0.11$ & -0.08 & $-0.45,0.30$ \\
\hline Metabolic syndrome & -0.05 & $-0.09,-0.02$ & -0.05 & $-0.09,-0.02$ & -0.04 & $-0.08,-0.01$ & -0.001 & $-0.02,0.02$ \\
\hline \multicolumn{9}{|l|}{ Women } \\
\hline Waist circumference $(\mathrm{cm})$ & -0.14 & $-0.53,0.25$ & -0.12 & $-0.51,0.27$ & -0.07 & $-0.47,0.32$ & - & - \\
\hline $\operatorname{BMI}\left(\mathrm{kg} / \mathrm{m}^{2}\right)$ & -0.11 & $-0.28,0.06$ & -0.11 & $-0.28,0.07$ & -0.08 & $-0.26,0.09$ & - & - \\
\hline Fasting glucose $(\mathrm{mmol} / \mathrm{l})$ & -0.01 & $-0.03,0.002$ & -0.01 & $-0.03,0.002$ & -0.01 & $-0.03,0.004$ & -0.02 & $-0.03,0.001$ \\
\hline Fasting insulin $(\mathrm{mU} / \mathrm{l}) \|$ & -0.10 & $-0.24,0.04$ & $-0 \cdot 10$ & $-0.24,0.04$ & -0.06 & $-0.20,0.08$ & -0.06 & $-0.19,0.06$ \\
\hline HOMA-IR & -0.03 & $-0.06,0.01$ & -0.03 & $-0.06,0.01$ & -0.02 & $-0.05,0.02$ & -0.02 & $-0.05,0.01$ \\
\hline TAG $(\mathrm{mmol} / \mathrm{l})$ & -0.01 & $-0.03,0.01$ & -0.01 & $-0.03,0.01$ & -0.01 & $-0.03,0.01$ & -0.01 & $-0.03,0.01$ \\
\hline Total cholesterol $(\mathrm{mmol} / \mathrm{l})$ & -0.03 & $-0.07,-0.004$ & -0.03 & $-0.07,0.004$ & -0.02 & $-0.06,0.01$ & -0.03 & $-0.07,0.01$ \\
\hline LDL-cholesterol (mmol/l) & -0.02 & $-0.06,0.01$ & -0.02 & $-0.06,0.01$ & -0.02 & $-0.05,0.02$ & -0.02 & $-0.06,0.01$ \\
\hline HDL-cholesterol (mmol/l/) & 0.001 & $-0.01,0.01$ & 0.001 & $-0.01,0.01$ & 0.001 & $-0.01,0.01$ & 0.001 & $-0.01,0.01$ \\
\hline Systolic blood pressure $(\mathrm{mmHg})$ & 0.08 & $-0.36,0.51$ & 0.06 & $-0.38,0.49$ & 0.10 & $-0.34,0.55$ & 0.11 & $-0.33,0.55$ \\
\hline Diastolic blood pressure $(\mathrm{mmHg})$ & -0.002 & $-0.38,0.37$ & -0.01 & $-0.38,0.37$ & -0.001 & $-0.38,0.38$ & 0.02 & $-0.35,0.38$ \\
\hline Metabolic syndrome & -0.03 & $-0.06,0.01$ & -0.03 & $-0.06,0.01$ & -0.02 & $-0.06,0.01$ & -0.02 & $-0.04,0.004$ \\
\hline
\end{tabular}

HOMA-IR, homeostasis model assessment-insulin resistance.

*Analyses for men adjusted for age and education; analyses for women adjusted for age, education and alcohol intake.

† Model 1 + leisure-time physical activity.

$\ddagger$ Model $2+$ overall dietary score (number of dietary guidelines met).

$\S$ Model 3 + waist circumference.

$\| 1 \mathrm{mU} / \mathrm{l}=6.00 \mathrm{pmol} / \mathrm{l}$ 
factors only in men. Another cross-sectional study reported a higher eating frequency was associated with lower cholesterol levels in 50-89-year-old men and women ${ }^{(40)}$. After menopause, women store more fat centrally ${ }^{(41)}$ and this may explain why significant results were observed in older women and not in the present study. Adjusting for obesity and fat distribution reduced the differences observed in that study.

There are several limitations to the present study. Due to the cross-sectional analyses, we are unable to determine the direction of the association. Overweight or obese participants may have reduced their eating frequency in an attempt to lose weight or not reported some eating occasions. However, excluding those on a weight-loss diet did not change the present results, and as our participants were from a populationbased sample and were not recruited for being overweight or obese, there may be few post hoc changes in diet to reduce weight. The meal pattern chart was only completed for the previous day, and this may not be representative of the participants' normal eating patterns. However, we expect that any misclassification would be random in nature and would not bias the present results. National data from the USA show that the day-to-day variation in an individual's eating frequency (measured using one $24 \mathrm{~h}$ recall and $2 \mathrm{~d}$ diet records) is relatively large compared with the betweensubject variation ${ }^{(42)}$. This suggests that multiple days are needed to measure an individual's eating frequency with precision. Nevertheless, we were able to find significant associations with data for only $1 \mathrm{~d}$ for men and similar, nonsignificant, associations for women. The FFQ did not collect information on portion size, and therefore we were unable to adjust our analysis for energy intake. However, even if we had self-reported portion size as well as food frequency, our estimates of energy intake would be prone to measurement error. We did take into account key determinants of energy intake by stratifying the analysis by sex and adjusting for age and physical activity. We also adjusted for overall diet quality. However, residual confounding from energy intake cannot be ruled out and experimental studies are needed to determine whether the associations are mediated by energy intake.

Strengths include the large sample size and stratification of the analyses by men and women to observe sex differences. We were able to examine the associations between eating frequency and a variety of cardiometabolic risk factors. We had data on a large range of sociodemographic and lifestyle factors and dietary variables which we were able to include in our models to reduce the risk of confounding.

In conclusion, a higher eating frequency was associated with reduced cardiometabolic risk factors in men. The associations were mostly mediated by waist circumference. There is some evidence that individuals reduce energy intake at other eating occasions when snacking is sustained ${ }^{(43)}$. However, if portion sizes and energy density of the meals are not reduced enough to compensate for the higher eating frequency, eating smaller meals more frequently may result in weight gain. Therefore, more studies are needed to investigate the effect of eating frequency on appetite and energy intake, before recommending a higher eating frequency.

\section{Acknowledgements}

We gratefully acknowledge the contributions of the study's project manager, Marita Dalton, all other project staff and the study participants. This study was funded by grants from the National Health and Medical Research Council, the National Heart Foundation, the Tasmanian Community Fund and Veolia Environmental Services. We gratefully acknowledge the study sponsors Sanitarium, ASICS and Target. S. A. M. was supported by a National Heart Foundation of Australia Postdoctoral Fellowship and S. L. G. was supported by a National Health and Medical Research Public Health Postdoctoral Fellowship. The funding bodies and sponsors had no input into the study design; collection, analysis and interpretation of the data; the writing of the report; or in the decision to submit the paper for publication. The authors declare no conflict of interest. The authors' responsibilities were as follows: K. J. S. performed the statistical analysis and drafted the manuscript; L. B. provided statistical support and critically revised the manuscript; S. A. M. provided nutritional advice and critically revised the manuscript; S. L. G. critically revised the manuscript; T. D. was involved in the conceptualisation of the study and critically revised the manuscript; A. J. V. was involved in the conceptualisation of the study, acquired the data and critically revised the manuscript.

\section{References}

1. Popkin BM \& Duffey KJ (2010) Does hunger and satiety drive eating anymore? Increasing eating occasions and decreasing time between eating occasions in the United States. Am J Clin Nutr 91, 1342-1347.

2. Fabry P, Fodor J, Hejl Z, et al. (1968) Meal frequency and ischaemic heart-disease. Lancet ii, 190-191.

3. Bellisle F, McDevitt R \& Prentice AM (1997) Meal frequency and energy balance. Br J Nutr 77, Suppl. 1, S57-S70.

4. Duval K, Strychar I, Cyr MJ, et al. (2008) Physical activity is a confounding factor of the relation between eating frequency and body composition. Am J Clin Nutr 88, 1200-1205.

5. Summerbell CD, Moody RC, Shanks J, et al. (1996) Relationship between feeding pattern and body mass index in 220 free-living people in four age groups. Eur J Clin Nutr $\mathbf{5 0}$, 513-519.

6. Drummond SE, Crombie NE, Cursiter MC, et al. (1998) Evidence that eating frequency is inversely related to body weight status in male, but not female, non-obese adults reporting valid dietary intakes. Int J Obes Relat Metab Disord 22, 105-112.

7. Holmback I, Ericson U, Gullberg B, et al. (2010) A high eating frequency is associated with an overall healthy lifestyle in middle-aged men and women and reduced likelihood of general and central obesity in men. Br J Nutr 104, 1065-1073.

8. Palmer MA, Capra S \& Baines SK (2009) Association between eating frequency, weight, and health. Nutr Rev 67, 379-390.

9. Speechly DP \& Buffenstein R (1999) Greater appetite control associated with an increased frequency of eating in lean males. Appetite 33, 285-297.

10. Speechly DP, Rogers GG \& Buffenstein R (1999) Acute appetite reduction associated with an increased frequency of eating in obese males. Int $J$ Obes Relat Metab Disord 23, 1151-1159. 
11. Cameron JD, Cyr MJ \& Doucet E (2010) Increased meal frequency does not promote greater weight loss in subjects who were prescribed an 8-week equi-energetic energyrestricted diet. Br I Nutr 103, 1098-1101.

12. Bhutani S \& Varady KA (2009) Nibbling versus feasting: which meal pattern is better for heart disease prevention? Nutr Rev 67, 591-598.

13. Dwyer T \& Gibbons LE (1994) The Australian Schools Health and Fitness Survey. Physical fitness related to blood pressure but not lipoproteins. Circulation 89, 1539-1544.

14. Berteus Forslund H, Lindroos AK, Sjostrom L, et al. (2002) Meal patterns and obesity in Swedish women - a simple instrument describing usual meal types, frequency and temporal distribution. Eur J Clin Nutr 56, 740-747.

15. McNaughton SA, Ball K, Crawford D, et al. (2008) An index of diet and eating patterns is a valid measure of diet quality in an Australian population. J Nutr 138, 86-93.

16. Mishra G, Ball K, Arbuckle J, et al. (2002) Dietary patterns of Australian adults and their association with socioeconomic status: results from the 1995 National Nutrition Survey. Eur J Clin Nutr 56, 687-693.

17. Savige GS, Ball K, Worsley A, et al. (2007) Food intake patterns among Australian adolescents. Asia Pac J Clin Nutr 16, 738-747.

18. Worsley A, Blasche R, Ball K, et al. (2003) Income differences in food consumption in the 1995 Australian National Nutrition Survey. Eur J Clin Nutr 57, 1198-1211.

19. Australian Bureau of Statistics (1998) National Nutritional Survey Users' Guide 1995. Canberra: ABS.

20. Coyne T, Ibiebele TI, McNaughton S, et al. (2005) Evaluation of brief dietary questions to estimate vegetable and fruit consumption - using serum carotenoids and red-cell folate. Public Health Nutr 8, 298-308.

21. Smith A, Kellet E \& Schmerlaib Y (1998) The Australian Guide to Healthy Eating. Canberra: Commonwealth Department of Health and Family Sevices.

22. Smith KJ, McNaughton SA, Gall SL, et al. (2009) Takeaway food consumption and its associations with diet quality and abdominal obesity: a cross-sectional study of young adults. Int J Behav Nutr Phys Act 6, 29.

23. Friedewald WT, Levy RI \& Fredrickson DS (1972) Estimation of the concentration of low-density lipoprotein cholesterol in plasma, without use of the preparative ultracentrifuge. Clin Chem 18, 499-502.

24. Smith KJ, Gall SL, McNaughton SA, et al. (2010) Skipping breakfast: longitudinal associations with cardiometabolic risk factors in the Childhood Determinants of Adult Health Study. Am J Clin Nutr 92, 1316-1325.

25. Wijndaele K, Beunen G, Duvigneaud N, et al. (2006) A continuous metabolic syndrome risk score: utility for epidemiological analyses. Diabetes Care 29, 2329.

26. Craig CL, Marshall AL, Sjostrom M, et al. (2003) International physical activity questionnaire: 12 -country reliability and validity. Med Sci Sports Exerc 35, 1381-1395.

27. Salmon J, Owen N, Crawford D, et al. (2003) Physical activity and sedentary behavior: a population-based study of barriers, enjoyment, and preference. Health Psychol 22 , $178-188$.

28. Australian Government Department of Health and Ageing (2006) Standard Drink Guide. Canberra: Australian Government Department of Health and Ageing. http://www.alco hol.gov.au/internet/alcohol/publishing.nsf/Content/standard (updated 2006; cited 20 June 2008).

29. Jenkins DJ, Khan A, Jenkins AL, et al. (1995) Effect of nibbling versus gorging on cardiovascular risk factors: serum uric acid and blood lipids. Metabolism 44, 549-555.

30. Jenkins DJ, Wolever TM, Vuksan V, et al. (1989) Nibbling versus gorging: metabolic advantages of increased meal frequency. $N$ Engl J Med 321, 929-934.

31. Powell JT, Franks PJ \& Poulter NR (1999) Does nibbling or grazing protect the peripheral arteries from atherosclerosis? J Cardiovasc Risk 6, 19-22.

32. Rashidi MR, Mahboob S \& Sattarivand R (2003) Effects of nibbling and gorging on lipid profiles, blood glucose and insulin levels in healthy subjects. Saudi Med J 24, 945-948.

33. Taylor MA \& Garrow JS (2001) Compared with nibbling, neither gorging nor a morning fast affect short-term energy balance in obese patients in a chamber calorimeter. Int $J$ Obes Relat Metab Disord 25, 519-528.

34. Greenland S (1989) Modeling and variable selection in epidemiologic analysis. Am J Public Health 79, 340-349.

35. Australian Bureau of Statistics (2006) Census of Population and Housing Table: Social Marital Status by Age by Sex for Time Series, Australia. Canberra: ABS (Catalog no. 20680).

36. Australian Bureau of Statistics (2001) Census of Population and Housing Table: Occupation by Sex, Australia. Canberra: ABS (Catalogue no. 20680).

37. Australian Bureau of Statistics (2006) National Health Survey 2004-05: Summary of Results. Canberra: ABS (Cat. no. 4364.0).

38. de Koning L, Merchant AT, Pogue J, et al. (2007) Waist circumference and waist-to-hip ratio as predictors of cardiovascular events: meta-regression analysis of prospective studies. Eur Heart J 28, 850-856.

39. Yannakoulia M, Melistas L, Solomou E, et al. (2007) Association of eating frequency with body fatness in pre- and postmenopausal women. Obesity (Silver Spring) 15, 100-106.

40. Edelstein SL, Barrett-Connor EL, Wingard DL, et al. (1992) Increased meal frequency associated with decreased cholesterol concentrations; Rancho Bernardo, CA, 1984-1987. Am J Clin Nutr 55, 664-669.

41. Ley CJ, Lees B \& Stevenson JC (1992) Sex- and menopauseassociated changes in body-fat distribution. Am J Clin Nutr 55, 950-954.

42. Longnecker MP, Harper JM \& Kim S (1997) Eating frequency in the Nationwide Food Consumption Survey (U.S.A.), 1987-1988. Appetite 29, 55-59.

43. Kirk T \& Crursiter M (1999) Long-term snacking intervention did not lead to weight gain in free-living man. Scand J Nutr 2, Suppl. 34, 3-17. 